\title{
Preventative effect of Astragalus flavescens on hepatic fibrosis in rats and its mechanism of action
}

\author{
RONG LI ${ }^{1,2}$, GUANGRONG DAI $^{3}$, MENGYUN ZHAO $^{1}$, YONGHONG ZHANG ${ }^{1}$, \\ LI HUI $^{1}$, XUELI ZHANG ${ }^{1}$ and BIN JIN ${ }^{1}$ \\ ${ }^{1}$ Department of Gastroenterology, The First Hospital of Xi'an City, Xi'an, Shaanxi 710002; \\ ${ }^{2}$ The Third Department of Internal Medicine, The Fifth Hospital of Xi'an City, Xi'an, Shaanxi 710082; \\ ${ }^{3}$ Department of Gastroenterology, The Affiliated Hospital of Yan'an University, \\ Yan'an, Shaanxi 716000, P.R. China
}

Received March 16, 2013; Accepted June 27, 2013

DOI: $10.3892 /$ etm.2013.1232

\begin{abstract}
The aim of this study was to investigate the preventative effect of Astragalus flavescens on hepatic fibrosis in rats and its mechanism of action. A total of 60 rats were randomly divided into normal control, model control, high-dose treatment and low-dose treatment groups, and a hepatic fibrosis model was established. The high- and low-dose treatment groups were treated with $2 \mathrm{~g} / 100 \mathrm{~g}$ and $0.5 \mathrm{~g} / 100 \mathrm{~g}$ Astragalus flavescens, respectively, once a day. Eight weeks following the initiation of treatment, the liver specimens of the rats were stained and observed under a light microscope. Hepatic fibrosis indices, specifically, type III precollagen (PC III), type IV collagen (C IV), hyaluronic acid (HA) and laminin (LN), were detected. Furthermore, the expression and localization of the hepatic fibrosis-related factors transforming growth factor- $\beta 1$ (TGF- $\beta 1$ ), connective tissue growth factor (CTGF) and platelet-derived growth factor-BB (PDGF-BB) were determined. The serum levels of hepatic fibrosis indices, and the liver tissue levels of hepatic fibrosis-related factors and collagen surface density in the model control group and the high- and low-dose treatment groups were significantly higher compared with those of the normal control group $(\mathrm{P}<0.05)$. In addition, the values in the two treatment groups were significantly lower compared with those of the model control group $(\mathrm{P}<0.05)$. The present study demonstrated that Astragalus flavescens effectively prevents hepatic fibrosis in rats. A possible mechanism for this is that it may reduce the expression levels of TGF- $\beta 1$, PDGF-BB and CTGF, thereby inhibiting the activation of
\end{abstract}

Correspondence to: Dr Guangrong Dai, Department of Gastroenterology, The Affiliated Hospital of Yan'an University, 250 Zhongxin Street, Yan'an, Shaanxi 716000, P.R. China

E-mail: guangrongdai123@163.com

Key words: Astragalus flavescens, hepatic fibrosis, prevention, mechanism hepatic stellate cells and specifically blocking the signal transduction pathway of hepatic fibrosis.

\section{Introduction}

Hepatic fibrosis is a disease characterized by the abnormal hyperplasia of fibrous connective tissue in the liver, due to hepatocellular necrosis and inflammatory stimulation. It is the result of increased synthesis and decreased degradation of the extracellular matrix (ECM). Hepatic fibrosis is a common pathological process of all chronic liver diseases, and is the necessary prerequisite for liver cirrhosis (1). At present, it is mainly considered that the process of hepatic fibrosis is reversible, and its prevention and treatment is important for the prevention of liver cirrhosis (2). In recent years, studies concerned with the blockade or reversal of hepatic fibrosis have become an important topic in medicine worldwide (3-5). Due to increased investigation into the development of hepatic fibrosis (6-9), considerable progress has been made in the treatment of hepatic fibrosis with the emergence of novel synthetic drugs. However, the majority of these drugs are in clinical trials, with uncertain antifibrotic efficacy and significant side-effects.

At present, there are a number of single and compound prescriptions of traditional Chinese medicine that have demonstrated clear efficacy and marginal side-effects, and it has been suggested they may serve as potential treatments for hepatic fibrosis $(10,11)$. Astragalus flavescens, a compound prescription of Chinese herbal medicine, contains Radix Astragali, Radix Scutellariae and Flavescent Sophora. Astragalus flavescens has been utilized in the treatment of chronic liver disease for $>10$ years and has shown curative effects. It has been clinically demonstrated that Astragalus flavescens is effective in receding jaundice, detumescence, retracting the spleen, reducing ascites, lowering transaminase activity, increasing serum albumin levels and improving the prothrombin time. Clinical studies have indicated that Astragalus flavescens is able to regulate the immunity and scavenge oxygen free radicals, as well as exhibiting anti-viral and -tumor effects. In addition, the prescription for 
Table I. Comparisons of serum hepatic fibrosis indices in different groups.

Hepatic fibrosis indices $(\mu \mathrm{g} / \mathrm{l})$

\begin{tabular}{lccccc}
\cline { 3 - 5 } Groups & \multirow{2}{*}{ No. of rats } & PC III & C IV & HA & LN \\
\hline Normal control & 15 & $13.20 \pm 1.12$ & $4.90 \pm 0.62$ & $104.36 \pm 25.30$ & $27.46 \pm 6.56$ \\
Model control & 15 & $40.01 \pm 0.52^{\mathrm{a}}$ & $20.56 \pm 0.23^{\mathrm{a}}$ & $315.20 \pm 98.39^{\mathrm{a}}$ & $70.11 \pm 10.02^{\mathrm{a}}$ \\
Low-dose treatment & 15 & $34.20 \pm 0.82^{\mathrm{a}, \mathrm{b}}$ & $14.52 \pm 0.42^{\mathrm{a}, \mathrm{b}}$ & $185.20 \pm 18.21^{\mathrm{a}, \mathrm{b}}$ & $59.54 \pm 7.58^{\mathrm{a}, \mathrm{b}}$ \\
High-dose treatment & 15 & $19.56 \pm 0.98^{\mathrm{a}-\mathrm{c}}$ & $7.98 \pm 0.91^{\mathrm{a}-\mathrm{c}}$ & $137.25 \pm 19.89^{\mathrm{a}, \mathrm{b}}$ & $48.59 \pm 9.82^{\mathrm{a}-\mathrm{c}}$
\end{tabular}

Data are expressed as the mean \pm standard deviation. ${ }^{\mathrm{a}} \mathrm{P}<0.05$ compared with the normal control group; ${ }^{\text {b }}<0.05$ compared with the model control group and ${ }^{\mathrm{c}} \mathrm{P}<0.05$ compared with the low-dose treatment group. PC III, type III precollagen; C IV, type IV collagen; HA, hyaluronic acid; LN, laminin.

Astragalus flavescens is low in cost and convenient to use; therefore, it has good developmental value. The present study investigated the preventative effects of Astragalus flavescens on liver fibrosis in rats and its mechanism of action. The study aimed to provide a reliable experimental basis for the further application of Astragalus flavescens in the treatment of hepatic fibrosis.

\section{Materials and methods}

Experimental groups. A total of 60 male Wistar rats (clean grade; average weight, $180 \mathrm{~g}$ ), purchased from the Animal Experimental Center of the Fourth Military Medical University (Xi'an, China), were randomly divided into normal control, model control, high-dose treatment and low-dose treatment groups $(n=15$ rats per group). This study was carried out in strict accordance with the recommendations in the Guide for the Care and Use of Laboratory Animals of the National Institutes of Health (8th edition, 2011). The animal use protocol was reviewed and approved by the Institutional Animal Care and Use Committee (IACUC) of the First Hospital of Xi'an City (Xi'an, China). In the normal control group, a normal diet and water were freely available, $0.9 \% \mathrm{NaCl}$ was administered to the rats by gavage daily and peanut oil was administered by subcutaneous injection at a dose of $0.5 \mathrm{ml} / 100 \mathrm{~g}$ on the first day and $0.3 \mathrm{ml} / 100 \mathrm{~g}$ once every 4 days thereafter. In the model control group, according to a modification of composite factor modeling methods $(12,13)$, rats were subcutaneously injected with a mixture of $40 \% \mathrm{CCl}_{4}$ and peanut oil at a dose of $0.5 \mathrm{ml} / 100 \mathrm{~g}$ on the first day and $0.3 \mathrm{ml} / 100 \mathrm{~g}$ once every 4 days thereafter. The rats were fed with freely available compound feed containing $79.5 \%$ pure flour, $20 \%$ lard and $0.5 \%$ cholesterol, and water was the only drink. In the high- and low-dose treatment groups, the modeling method was the same as that in the model control group; however, the rats were additionally treated with Astragalus flavescens (2 g crude drug/g powder; Xi'an Chinese Traditional Medicine Oral Tablet Factory, Xi'an, China) by gavage, once a day. The dosages were $2 \mathrm{~g} / 100 \mathrm{~g}$ weight and $0.5 \mathrm{~g} / 100 \mathrm{~g}$ weight, respectively. Eight weeks following the initiation of treatment, all rats were sacrificed and heart, blood and liver specimens were obtained.
Hepatic fibrosis indices. The hepatic fibrosis indices, specifically, type III precollagen (PC III), type IV collagen (C IV), hyaluronic acid (HA) and laminin (LN), in the rat serum were detected by specific personnel in the isotope department using the radioimmunoassay method.

Liver tissue specimen observation. Rat liver tissue specimens were stained with Masson's trichrome $(14,15)$, followed by observation under a light microscope. The collagen surface density in the liver tissue was calculated as follows: Collagen surface density $(\%)=($ collagen area/viewed area $) \times 100$

Hepatic fibrosis-related factors. Liver tissue paraffin sections were prepared and dewaxed, enzyme closure was performed using with $3 \%$ hydrogen peroxide and antigen retrieval with citrate buffer. After closing non-specific sites using non-immune goat serum, primary antibody (rabbit anti-rat TGF- $\beta 1$ polyclonal antibody, rabbit anti-rat PDGF-BB polyclonal antibody and rabbit anti-rat CTGF polyclonal antibody; Wuhan Boster Biological Technology, Ltd., Wuhan, China) with 1:50 dilution using PBS was added, followed by incubation at $4^{\circ} \mathrm{C}$ overnight. After adding polymer enhancer and PBS washing, $50 \mu \mathrm{l}$ of horseradish peroxidase-labeled secondary antibody polymer was added by drops to each section, followed by incubation at $37^{\circ} \mathrm{C}$ for $30 \mathrm{~min}$ and $3 \mathrm{PBS}$ washes. After coloration, counterstain and mounting, the sections were observed in Q550CW image acquisition and analysis system (Leica Science Lab, Berlin, Germany). PBS replacing primary antibody was used as a blank, normal serum replacing secondary antibody was used as a negative control. No coloration was regarded as a negative result. TGF- $\beta 1, \mathrm{CTGF}$ and PDGF were stained in the cytoplasm and cytomembrane. The brown or dark brown granular staining was defined as a positive result, and the staining significantly darker than background or no background staining referred to positively stained cells. Ten visual fields of each section were selected and the ratio of positive cell area to liver visual field area $\left(\mu \mathrm{m}^{2} / \mu \mathrm{m}^{2}\right)$ was calculated. The broad-spectrum immunohistochemistry EliVision ${ }^{\mathrm{TM}}$ plus kit was provided by Fuzhou Maixin Biotechnology Development Co., Ltd. (Fuzhou, China).

Statistical analysis. Data are expressed as the mean \pm standard deviation. Statistical analysis was performed using 
Table II. Comparisons of collagen surface density in different groups.

\begin{tabular}{lcc}
\hline Group & No. of rats & $\begin{array}{c}\text { Collagen surface } \\
\text { density }(\%)\end{array}$ \\
\hline Normal control & 15 & $4.83 \pm 2.78$ \\
Model control & 15 & $24.31 \pm 3.55^{\mathrm{a}}$ \\
Low-dose treatment & 15 & $18.02 \pm 3.64^{\mathrm{a}, \mathrm{b}}$ \\
High-dose treatment & 15 & $7.97 \pm 1.06^{\mathrm{a}-\mathrm{c}}$ \\
\hline
\end{tabular}

${ }^{\text {a }} \mathrm{P}<0.05$ compared with the normal control group; ${ }^{\mathrm{b}} \mathrm{P}<0.05 \mathrm{com}-$ pared with the model control group and ${ }^{\mathrm{c}} \mathrm{P}<0.05$ compared with the low-dose treatment group.

SPSS software, version 11.5 (SPSS, Inc., Chicago, IL, USA). The Student's t-test was used to analyze the differences between two groups, and single factor analysis of variance and Student-Newman-Keuls tests were conducted for comparisons among multiple groups. $\mathrm{P}<0.05$ and $\mathrm{P}<0.01$ were considered to indicate a statistically significant difference.

\section{Results}

Comparison of serum hepatic fibrosis indices. The serum levels of hepatic fibrosis indices in the model control and low- and high-dose treatment groups were significantly increased compared with those in the normal control group $(\mathrm{P}<0.05)$, and those in the two treatment groups were significantly lower than those in the model control group $(\mathrm{P}<0.05$; Table I). The levels of PC III, C IV and LN in the high-dose treatment group were significantly lower than those in the low-dose treatment group $(\mathrm{P}<0.05)$; however, no significant difference was identified in the HA levels between the two treatment groups.

Morphological changes. The collagen surface densities in the model control and low- and high-dose treatment groups were significantly increased compared with that in the normal control group $(\mathrm{P}<0.05$; Table II). In addition, the collagen surface density in the two treatment groups was significantly lower than that in the model control group $(\mathrm{P}<0.05)$. Moreover, the collagen surface density in the high-dose treatment group was significantly lower than that in the low-dose treatment group $(\mathrm{P}<0.05)$.

Expression of hepatic fibrosis-related factors. The expression levels of the hepatic fibrosis-related factors TGF- $\beta 1$, CTGF and PDGF-BB in the different groups are shown in Table III. The expression levels of the three hepatic fibrosis-related factors in the model control group and the two treatment groups were significantly increased compared with those in the normal control group $(\mathrm{P}<0.05)$. Additionally, the expression levels of these factors in the two treatment groups were significantly lower than those in the model control group $(\mathrm{P}<0.05)$.

Expression of TGF- $\beta 1$ was predominantly identified in the cytoplasm, and infrequently observed in the cytomembrane.
The normal control group demonstrated weak expression of TGF- $\beta 1$ in the cytoplasm of liver cells, with the distribution focused in the portal area and surrounding the central vein wall (Fig. 1A). TGF- $\beta 1$ expression in the model control group was significantly increased compared with that of the normal control group, and the majority of the expression was observed in the portal area, central vein wall, proliferated fibrous septum, liver sinus wall, small bile duct cells, inflammatory cells and fatty and hepatic cells with steatosis and hydropic degeneration (Fig. 1B). The expression of TGF- $\beta 1$ in the lowand high-dose treatment groups was significantly reduced compared with that of the model control group, and was mainly evident in the portal area, proliferated fibrous septum and inflammatory cells. Furthermore, the level of TGF- $\beta 1$ expression in the high-dose treatment group was lower (Fig. 1C).

Expression of CTGF was observed in the cytoplasm and cytomembrane (as brown granules). In the normal control group, CTGF expression was negligible (Fig. 1D). By contrast, in the model control group, CTGF expression was significantly increased; the protein was predominantly identified in the spindle cells with processes and branches in the fibrosis portal area and fibrous septa [activated hepatic stellate cells (HSCs)], and inflammatory cells (Fig. 1E). The level of CTGF expression in the two treatment groups was significantly lower than that in the model control group, and that in the high-dose treatment group was the lowest (Fig. 1F).

Similarly to CTGF, PDGF-BB was expressed in the cytoplasm and cytomembrane. In the normal control group, no PDGF-BB expression was observed in hepatic cells and weak PDGF-BB expression was identified in the vascular wall, portal area and interstitial cells. In the model control group, the number of PDGF-BB-positive granules was significantly increased. Hyperplasia was most evident in the fibrous septa and portal area, with specific distribution in the infiltration area of inflammatory cells (Fig. 1G). The PDGF-BB expression level in the low- and high-dose treatment groups was significantly decreased compared with that of the model control group (Fig. 1H shows the expression in the high-dose treatment group).

\section{Discussion}

Modern Chinese medicine considers liver blood stasis to be the main pathogenesis of hepatic fibrosis, of which the essence is fibrous tissue hyperplasia, degeneration and microcirculation disturbance. Therefore, activating blood and dissolving stasis is important for the treatment of hepatic fibrosis $(16,17)$. Astragalus flavescens is proposed to be involved in activating blood and dissolving stasis, strengthening body resistance, supplementing qi, heat-clearing and detoxifying, removing dampness and receding jaundice. It may provide multi-channel, -level and -target prevention of and treatment for hepatic fibrosis.

Previous studies have demonstrated that, during the process of hepatic fibrosis, HSCs are activated and transformed into myofibroblast-like cells (18). This is important in the formation of hepatic fibrosis. Although there are a variety of cells involved in the induction of hepatic fibrosis, activated HSCs are the main cells that promote the deposition of a large quantity of ECM (19-22). The initiation and activation 
Table III. Expression levels of hepatic fibrosis-related factors in different groups.

\begin{tabular}{|c|c|c|c|c|}
\hline \multirow[b]{2}{*}{ Group } & \multirow[b]{2}{*}{ No. of rats } & \multicolumn{3}{|c|}{ Hepatic fibrosis-related factors $\left(\mu \mathrm{m}^{2} / \mu \mathrm{m}^{2}\right)$} \\
\hline & & TGF- $\beta 1$ & CTGF & PDGF-BB \\
\hline Normal control & 15 & $0.10 \pm 0.02$ & $0.03 \pm 0.01$ & $0.05 \pm 0.02$ \\
\hline Model control & 15 & $0.61 \pm 0.05^{\mathrm{a}}$ & $0.80 \pm 0.02^{\mathrm{a}}$ & $0.61 \pm 0.06^{\mathrm{a}}$ \\
\hline Low-dose treatment & 15 & $0.30 \pm 0.08^{\mathrm{a}, \mathrm{b}}$ & $0.11 \pm 0.05^{\mathrm{a}, \mathrm{b}}$ & $0.41 \pm 0.10^{\mathrm{a}, \mathrm{b}}$ \\
\hline High-dose treatment & 15 & $0.13 \pm 0.08^{\mathrm{a}, \mathrm{b}}$ & $0.05 \pm 0.09^{\mathrm{a}, \mathrm{b}}$ & $0.18 \pm 0.01^{\mathrm{a}, \mathrm{b}}$ \\
\hline
\end{tabular}

Data are expressed as the mean \pm standard deviation. ${ }^{\mathrm{a}} \mathrm{P}<0.05$ compared with the normal control group; ${ }^{\mathrm{P}}<0.05$ compared with the model control group. TGF- $\beta 1$, transforming growth factor- $\beta 1$; CTGF, connective tissue growth factor; PDGF-BB, platelet-derived growth factor-BB.
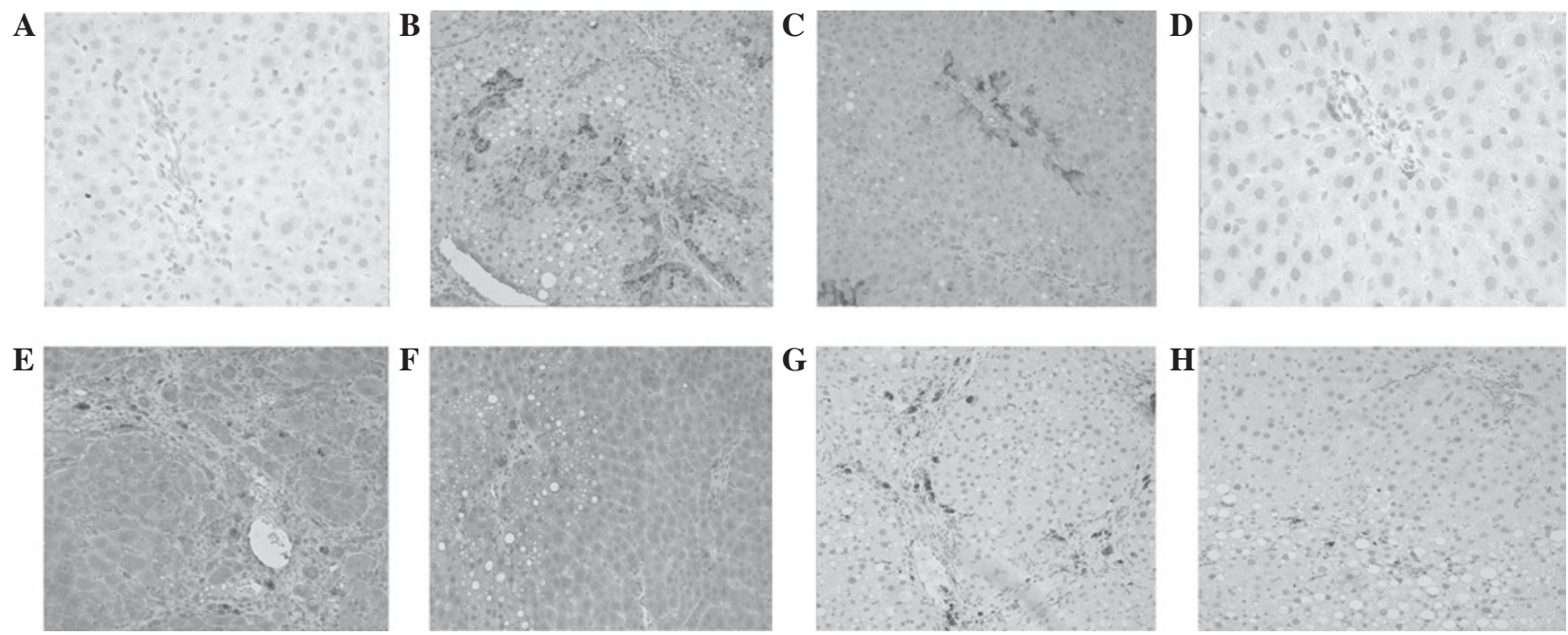

Figure 1. Immunohistochemical observations of the hepatic fibrosis related factors (A) transforming growth factor- $\beta 1$ (TGF- $\beta 1$ ) in the normal control group (magnification, $\mathrm{x} 400$ ); (B) TGF- $\beta 1$ in the model control group (magnification, $\mathrm{x} 200$ ); (C) TGF- $\beta 1$ in the high-dose treatment group (magnification, $\mathrm{x} 200$ ); (D) connective tissue growth factor (CTGF) in the normal control group (magnification, $\mathrm{x} 400$ ); (E) CTGF in the model control group (magnification, $\mathrm{x} 200$ ); (F) CTGF in the high-dose treatment group (magnification, $\mathrm{x} 200$ ); (G) platelet-derived growth factor-BB (PDGF-BB) in the model control group (magnification, $\mathrm{x} 400)$ and (H) PDGF-BB in the high-dose treatment group (magnification, $\mathrm{x} 200$ ).

of HSCs are mediated by TGF- $\beta 1$, which is an intermediary agent between HSC initiation and hepatic fibrosis (23), and is one of the most important factors determining hepatic fibrosis (24-26). During hepatic fibrosis, TGF- $\beta 1$ initiates and maintains the activation of HSCs in a paracrine and autocrine manner, and regulates the cell proliferation. Therefore, it is able to promote collagen gene transcription and ECM proliferation, and inhibit the synthesis and secretion of proteolytic enzymes, thus resulting in a reduction in ECM degradation. Once hepatic fibrosis is initiated, it continues and the gradually increased fibrosis results in cirrhosis. Therefore, the inhibition of TGF- $\beta 1$ production or the blocking of its biological activity may inhibit the activation of HSCs. This is considered to be one of the most promising methods of antifibrotic therapy (27). It has been proposed that TGF- $\beta 1$ is also involved in normal physiological activities, such as immune suppression and the inhibition of cell proliferation $(28,29)$. Therefore, when using drugs to inhibit TGF- $\beta 1$ expression in antifibrotic therapy, controlled doses are necessary.

CTGF is a downstream response element of TGF- $\beta 1$ and a central channel for the activation of HSCs (30). CTGF inhibitors are able to selectively block the fibrogenic effect of TGF- $\beta 1$, and this role of CTGF is more likely to influence the occurrence of fibrosis (30). Therefore, CTGF inhibitors may be used for the effective prevention and treatment of hepatic fibrosis (31). The present study demonstrated that following treatment with Astragalus flavescens, the hyperplasia of collagen fibers in rats with hepatic fibrosis was significantly reduced, and the expression levels of TGF- $\beta 1$ and CTGF in the fibrous septum were significantly inhibited. These results indicate that Astragalus flavescens is able to reduce the expression of TGF- $\beta 1$ and CTGF, inhibit the activation and proliferation of HSCs, and prevent the continued amplification effect of cell activation. In addition, it may reduce the generation of CTGF, thus selectively blocking the fibrogenic channel of TGF- $\beta 1$.

At present, it is considered that PDGF-BB is the most effective mitogenic factor for inducing $\mathrm{HSC}$ proliferation and the related signal transduction. PDGF-BB promotes the activation and division of HSCs and stimulates collagen synthesis (32-34). The current study identified that the localization of PDGF distribution was consistent with the 
sites at which HSC and collagen deposition are present. The expression levels of PDGF in the low- and high-dose treatment groups were significantly lower than that in the model control group. The results indicate that Astragalus flavescens inhibited the expression of PDGF and the proliferation and activation of HSCs, and may therefore prevent the formation of hepatic fibrosis.

\section{Acknowledgements}

This study was supported by the Xi'an Science and Technology Project (Spark Program Technology Fund; grant no. SF200212).

\section{References}

1. Crabb DW: Pathogenesis of alcoholic liver disease: newer mechanisms of injury. Keio J Med 48: 184-188, 1999.

2. Povero D, Busletta C, Novo E, et al: Liver fibrosis: a dynamic and potentially reversible process. Histol Histopathol 25: 1075-1091, 2010.

3. Svegliati Baroni G, D'Ambrosio L, Ferretti G, et al: Fibrogenic effect of oridative stress on rat hepatic stellate cells. Hepatology 27: 720-726, 1998

4. Hellerbrand C, Stefanovic B, Giordano F, Burchardt ER and Brenner DA: The role of TGF- $\beta 1$ in initiating hepatic stellate cell activation in vivo. J Hepatol 30: 77-87, 1999.

5. Tsrkamoto $\mathrm{H}$ : Is interleukin 10 antifibrogenic in chronic liver injury? Hepatology 28: 1707-1709, 1998.

6. Knittel T, Janneck T, Müller L, Fellmer P and Ramadori G: Transforming growth factor beta 1-regulated gene expression of Ito cells. Hepatology 24: 352-360, 1996.

7. Pinzani M, Milani S, Grappone C, Weber FL Jr, Gentilini P and Abboud HE: Expression of platelet-derived growth factor in model of acute liver injury. Hepatology 19: 701-707, 1994

8. Lasky JA, Ortiz LA, Tonthat B, et al: Connective tissues growth factor mRNA expression is upregulated in bleomycin-induced lung fibrosis. Am J Physiol 275: L365-L371, 1998.

9. Abraham DJ, Shiwen X, Black CM, Sa S, Xu Y and Leask A: Tumor necrosis factor alpha suppresses the induction of connective tissue growth factor by transforming growth factorbeta in normal and scleroderma fibroblasts. J Biol Chem 275: 15220-15225, 2000.

10. Chen MM, Lam A, Abraham JA, Schreiner GF and Joly AH: CTGF expression is induced by TGF- beta in cardiac fibroblasts and cardiac myocytes: a potential role in heart fibrosis. J Mot Cell Cardiol 32: 1805-1819, 2000

11. Sato S, Nagaoka T, Hasegawa M, Tamatani T, Nakanishi T, Takigawa M and Takehara K: Serum levels of connective tissue growth factor are elevated in patients with systemic sclerosis: association with extent of skin sclerosis and severity of pulmonary fibrosis. J Rheumatol 27: 149-154, 2000.

12. Guo $\mathrm{Y}$, Wang $\mathrm{H}$ and Zhang C: Establishment of rat precision-cut fibrotic liver slice technique and its application in verapamil metabolism. Clin Exp Pharmacol Physiol 34: 406-413, 2007.

13. Han DW, Ma XH and Zhao YC: Research of animal model of hepatic cirrhosis. Shanxi Medical Journal 4: 1-5, 1979 (In Chinese)

14. Xue KX, Yan HY and Liu TX: Immunohistochemistry study on collagen type I and III of sternomastoid muscle in congenital muscular torticollis. Journal of Xinxiang Medical College 22: 530-532, 2005 (In Chinese).

15. 15. Han TL, Wang M, Hong M, et al: The comparison and application of masson trichrome and he staining in histological paraffin sections of teeth in guinea pig. China Animal Husbandry \& Veterinary Medicine 38: 55-57, 2011 (In Chinese).
16. Lei N, Zheng SZ and Lu Y: Mechanisms and research progress of promoting blood circulation for removing blood stasis herbs in treating hepatic fibrosis. China Journal of TCM and Pharmacy 25: 265-268, 2010 (In Chinese)

17. Yang Q, Feng YY and Jiang SL: Experiences of professor Yao $\mathrm{Xi}$-xian in treating chronic hepatic fibrosis based on blood stasis theory. China Journal of TCM and Pharmacy 22: 168-171, 2007 (In Chinese).

18. Luk JM, Zhang QS, Lee NP, et al: Hepatic stellate cell-targeted delivery of M6P-HSA-glycyrrhetinic acid attenuates hepatic fibrogenesis in a bile duct ligation rat model. Liver Int 27 : 548-557, 2007.

19. Constandinou C, Henderson $\mathrm{N}$ and Iredale JP: Modeling liver fibrosis in rodents. Methods Mol Med 117: 237-250, 2005.

20. Saile B, Matthes N, Neubauer K, et al: Rat liver myofibroblasts and hepatic stellate cells differ in CD95-mediated apoptosis and response to TNF-alpha. Am J Physiol Gastrointest Liver Physiol 283: G435-G444, 2002.

21. Friedman SL: Molecular regulation of hepatic fibrosis, an integrated cellular response to tissue injury. J Biol Chem 275 . 2247-2250, 2000.

22. Nieto N, Greenwel P, Friedman SL, Zhang F, Dannenberg AJ and Cederbaum AI: Ethanol and arachidonic acid increase alpha 2(I) collagen expression in rat hepatic stellate cells overexpressing cytochrome $\mathrm{P} 4502 \mathrm{E} 1$. Role of $\mathrm{H}_{2} \mathrm{O}_{2}$ and cyclooxygenase-2. J Biol Chem 275: 20136-20145, 2000.

23. Zhang C, Zhu Y, Wan J, Xu H, Shi H and Lu X: Effects of Ginkgo biloba extract on cell proliferation, cytokines and extracellular matrix of hepatic stellate cells. Liver Int 26: 1283-1290, 2006.

24. Kuriyama S, Yokoyama F, Inoue H, et al: Sequential assessment of the intrahepatic expression of epidermal growth factor and transforming growth factor-beta1 in hepatofibrogenesis of a rat cirrhosis model. Int J Mol Med 19: 317-324, 2007.

25. Kaimori A, Potter J, Kaimori JY, Wang C, Mezey E and Koteish A: Transforming growth factor-betal induces an epithelial-to-mesenchymal transition state in mouse hepatocytes in vitro. J Biol Chem 282: 22089-22101, 2007.

26. Gressner AM, Weiskirchen R, Breitkopf K and Dooley S: Roles of TGF-beta in hepatic fibrosis. Front Biosci 7: d793-d807, 2002.

27. Tamatani T, Kobayashi H, Tezuka K, et al: Establishment of the enzyme-linked immunosorbent assay for connective tissue growth factor (CTGF) and its detection in the sera of biliary atresia. Biochem Biophys Res Commun 251: 748-752, 1998.

28. Song SL, Gong ZJ, Zhang QR, Huang TX and Wu SK: Changes and significance of cytokines and ultrastructure of experimental hepatic fibrosis in rats. Chinese Journal of Integrated Traditional and Western Medicine on Liver Diseases 14: 28-31, 2004 (In Chinese)

29. McCartney-Francis NL and Wahl SM: Transforming growth factor beta: a matter of life and death. J Leukoc Biol 55: 401-409, 1994.

30. Saegusa S, Isaji S and Kawarada Y: Changes in serum hyaluronic acid levels and expression of CD44 and CD44 mRNA in hepatic sinusoidal endothelial cells after major hepatectomy in cirrhotic rats. World J Surg 26: 694-699, 2002.

31. Blom IE, Goldschmeding R and Leask A: Gene regulation of connective tissue growth factor: new targets for antifibrotic therapy? Matrix Biol 21: 473-482, 2002.

32. Chen YX, Lu CH, Xie WF, et al: Effects of ribozyme targeting platelet-derived growth factor receptor beta subunit gene on the proliferation and apoptosis of hepatic stellate cells in vitro. Chin Med J (Engl) 118: 982-988, 2005.

33. Yang L, Zhang CZ and Zhu QJ: Kangxian ruangan keli inhibits hepatic stellate cell proliferation mediated by PDGF. World J Gastroenterol 9: 2050-2053,2003.

34. Guo J and Friedman SL: Hepatic fibrogenesis. Semin Liver Dis 27: 413-426, 2007. 